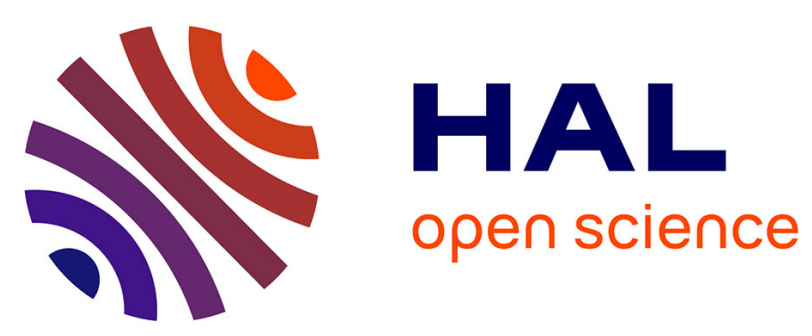

\title{
Natufian collective burial practice and cranial pigmentation: A reconstruction from Azraq 18 (Jordan) Fanny Bocquentin, Andrew Garrard
}

\section{To cite this version:}

Fanny Bocquentin, Andrew Garrard. Natufian collective burial practice and cranial pigmentation: A reconstruction from Azraq 18 (Jordan). Journal of Archaeological Science: Reports, 2016, 10, pp.693-702. 10.1016/j.jasrep.2016.05.030 . hal-02010589

\section{HAL Id: hal-02010589 \\ https://hal.parisnanterre.fr/hal-02010589}

Submitted on 7 Feb 2019

HAL is a multi-disciplinary open access archive for the deposit and dissemination of scientific research documents, whether they are published or not. The documents may come from teaching and research institutions in France or abroad, or from public or private research centers.
L'archive ouverte pluridisciplinaire HAL, est destinée au dépôt et à la diffusion de documents scientifiques de niveau recherche, publiés ou non, émanant des établissements d'enseignement et de recherche français ou étrangers, des laboratoires publics ou privés. 


\title{
Natufian collective burial practice and cranial pigmentation: A reconstruction from Azraq 18 (Jordan)
}

\author{
Fanny Bocquentin ${ }^{\mathrm{a}, *}$, Andrew Garrard ${ }^{\mathrm{b}}$ \\ a CNRS UMR 7041, Equipe Ethnologie Préhistorique. Maison de l'Archéologie et de l'Ethnologie, 21 allée de l'Université, 92023 Nanterre Cedex,

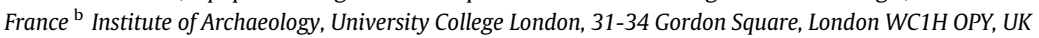

Keywords:

Early Natufian

Successive burials

Collective funerary space

Bone spatial distribution

Secondary bone handling

Cranial pigmentation

\begin{abstract}
A B S T R A C T
The collective grave from Azraq 18 in Jordan provides an exceptional case-study of Natufian burial treatment from a site outside what was traditionally regarded as the core settlement area of the Mediterranean zone. Despite the bones being in a poor state of preservation, the meticulous excavation and recording of the material from the burial pit permits the reconstruction of the funerary treatment of each individual and of the history of the collective burial feature through time. Through detailed osteological analysis, techniques for unravelling the formation processes involved in the creation of the commingled assemblage of bones are presented. These aid reconstruction of burial practices and the subsequent secondary handling of the skeletal remains. Amongst the collective graves known from the Natufian, Azraq 18 provides some of the best information on the various steps involved in their creation. In addition, two crania show traces of pigmentation attesting to elaborate and rare secondary treatment of skeletal material in Natufian contexts.
\end{abstract}

\section{Introduction}

\subsection{The Natufian cultural context}

The Natufian represents the final stage of the Levantine Epipalaeolithic (circa 15-11,600 cal BP) overlapping closely in time with the terminal Pleistocene Bølling-Allerød and Younger Dryas climatic events (Byrd, 2005). Although many features of the Natufian have antecedents in the earlier Epipalaeolithic (Maher et al., 2012), it is generally recognized as a period of increasingly long-term residence at sites in the most environmentally favourable areas of the Levantine Corridor, with a hierarchy of settlements ranging from large-scale base-camps with stone-built dwellings to more ephemeral small-scale campsites. These are distributed from the northern Negev to northern Syria with some suggestion of an extension of range in the Late Natufian (Valla, 2000, Bar-Yosef, 2002, Goring-Morris et al., 2009). There is evidence for an intensification in the use of certain plant foods, including investment in heavy ground-stone technology at the largest sites (Wright, 1994; Dubreuil, 2004) and for specialist hunting of mediumsized mammals and particularly gazelle, as well as a broadening in the use of smaller game (Stutz et al., 2009). Of particular note in relation to this article is the appearance of numerous graves in the vicinity of former dwelling areas within abandoned houses or, exceptionally, beneath

\footnotetext{
* Corresponding author.

E-mail addresses: fanny.bocquentin@cnrs.fr (F. Bocquentin), a.garrard@ucl.ac.uk (A. Garrard).
}

actively used occupation floors (Valla and Bocquentin, 2008; Bocquentin et al., 2013). There is generally a major expansion in surviving symbolic imagery from Natufian sites, including carving and engraving in bone, antler and stone, as well as body ornamentation (GoringMorris and Belfer-Cohen, 2010). The largest Natufian base camps have been found in the woodland and park woodland environments of the Levantine Corridor, while in the steppelands of the northern Negev and Sinai and of eastern Jordan and Syria sites are generally smallerscale. However, in eastern Jordan, two settlements have been excavated with burials: namely Azraq 31, which is located in the Azraq oases and features in this article, and more recently Shubayqa 1 lying to the south-east of Jebel Druze (Richter et al., 2014).

\subsection{Grouping the dead during the Natufian}

Burial customs in the Natufian period are documented through a series of circa 430 skeletons which have been unearthed to date (e.g. Garrod and Bate, 1937; Fiedel, 1979; Belfer-Cohen, 1988; Perrot and Ladiray, 1988; Webb and Edwards, 2002; Grosman et al., 2008; Weintsein-Evron, 2009; Lengyel et al., 2013). There is considerable variability in mortuary practice, but there do appear to be some common rules. Indeed, when undertaking comparative studies, some similarities related to sites, periods or biological factors such as kinship, age or sex are observed (Bocquentin, 2003; Bocquentin et al., 2010). Although about half of the burials are primary single graves, multiple graves where several individuals are grouped together inside the same funerary context are also well-known. This latter category of interment 
covers a wide variety of mortuary practices, and of situations (contemporaneous death of several individuals, successive deaths with a later regrouping of remains, or a sequence of burials resulting from a succession of deaths). Even though the processes are different, the archaeological evidence may appear to be very similar (e.g. Ubelaker, 1974).

The current focus of this contribution will be on graves in which several individuals were buried in the same funerary space (a simple pit or an elaborated structure) in delayed succession one after the other (multiple successive inhumations). The time span separating each interment must be long enough to be recognized by an anthropologist. That is to say, the process of decay of the most labile joints must have started. In this case, the succession of interments leads to their designation as a collective grave (Leclerc and Tarrête, 1997). Garrod and Bate (1937) suggested the existence of successive burials in the Natufian, and Bar-Yosef and Goren (1973) and Perrot and Ladiray (1988) demonstrated this some time ago. However, up to now, this specific category of grave is not fully understood. The way it was used, for whom, and for how long is unknown, as is the place this collective treatment holds within Natufian burial customs. Assemblages frequently described as a pile of disorganized bones contain the clues for disentangling the dynamics of the burial deposition allowing a better appreciation of the burial customs. The Natufian grave at Azraq 18 is presented below as a case-study.

\section{Material and methods}

\subsection{The Azraq 18 site}

The Natufian site of Azraq 18 was found during the course of the "Azraq Basin Prehistory Project" directed by one of the authors (AG) in the 1980s. The aim of this extensive survey and excavation project was to reconstruct the palaeoenvironmental and late Palaeolithic and Neolithic settlement history of this presently steppe and oasis region lying at the south-eastern margins of the Levantine Corridor. Previously, very little systematic research had been undertaken on the prehistoric communities of this region and their potential relations with those living in the more wooded environments of the Levantine Corridor (Garrard and Byrd, 2013).

The site was located within the Azraq Oases, in an area of silt dunes $\mathrm{c}$ $1.3 \mathrm{~km}$ south of the major perennial spring of Ain Soda and about $0.5 \mathrm{~km}$ west of the present shore of Qa Azraq (Garrard, 1991: 237). The surface spread of artifacts covered about 1400 sq. $\mathrm{m}$. and a single 6 sq. $\mathrm{m}$ trench was excavated in 1985 (unfortunately the site was destroyed the following year). The trench revealed $30-40 \mathrm{~cm}$ of cultural stratigraphy contained in carbonate indurated silts (Garrard and Byrd, 2013: 100103). At the base of the sequence was a pit containing the burials described in this paper and above was a dense occupational level of lithics, animal bones, ground stone fragments and a portion of a possible bone sickle haft (Garrard, 1991: 239). The fauna was predominantly cattle (Bos primigenius), wild ass (Equus hemionus) and gazelle (Gazella gazella), and in combination with the other species, was characteristic of what may be found in an ecotonal situation between wetland oasis and extensive steppe (Martin, 1994). In spite of the careful collection techniques used, and flotation of all the non-concreted sediments, no charcoal was found which could be used for dating. However, on the basis of extensive comparisons, the lithic industry studied by Brian Byrd was regarded as dating "somewhere between the middle of the Early Natufian and an early stage of the Late Natufian (between c 1413,000 cal BP)" (Garrard and Byrd, 2013: 287-293, 388).

\subsection{The grave}

The Azraq 18 grave was found cut into sterile sediments $25 \mathrm{~cm}$ beneath the basal level of the overlying Natufian occupation. In the immediate layer above and at the perimeter of the burial feature (in square 4), one complete and several fragmented Bos primigenius horn cores were found, and the complete one was placed in an arched position as though

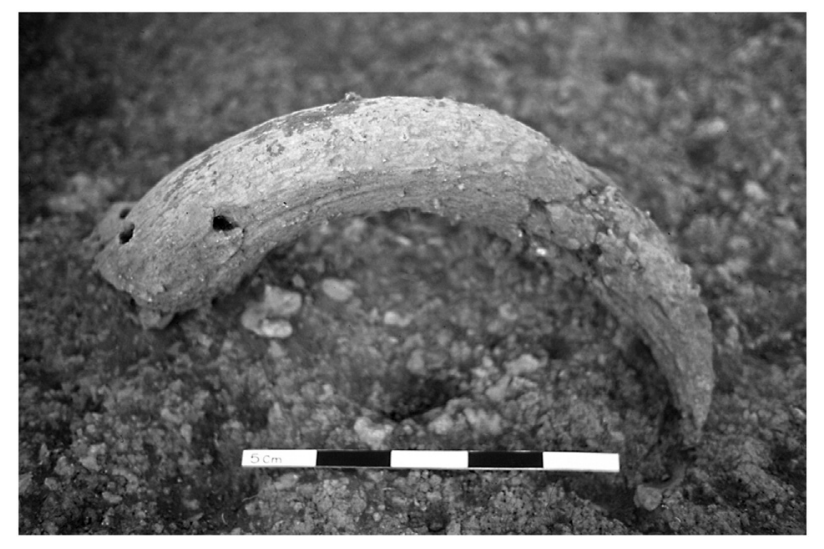

Fig. 1. Horn core of Bos primigenius which was placed in an arched position in the layer above the grave and at the perimeter or the burial area. It has two perforations cut in its base and one higher up.

its ends were pushed into soft soil. This particular horn core had two perforations cut into its base and one further up (Fig. 1). These remains may well have been associated with the burial pit or served as a marker. The human bones were distributed mainly over the western part of metre square 3 with some extensions into squares 2, 4 and 6 (Fig. 2). No well-defined limit to the burial pit was visible. Because some of the bones extended into the section of the trench it is likely that the grave continued beyond the excavated area (Garrard, 1991). The human remains were numbered from 1 to 212 and drawn on plans either individually or sometimes as a cluster of fragmented bones. Altogether about 320 fragments of bone were collected from the grave. ${ }^{1}$ Based on the scarcity of some anatomical elements and on the general arrangement of the bones, a preliminary report on these remains suggested that this assemblage resulted from the secondary burial of a maximum of 11 individuals (8 adults and 3 immature individuals) (Garrard, 1991: $240){ }^{2}$ However, the much more detailed osteological analysis presented in this article makes another interpretation more likely. As will be seen from Fig. 3, the state of preservation of the bones is extremely poor. Epiphyses and spongy bone are virtually absent. Diaphyses are highly fragmented, and sometimes eroded. The fragmentation is part of an early stage of the taphonomic process, which preceded the mineralization of the bones. Fragile axial elements such as vertebrae and ribs are poorly represented. Moreover, most of the remains are heavily encrusted with calcareous concretions. The authors attempted to carefully clean the bones using $10 \%$ acetic acid, but this process was unsuccessful due to the thickness of the calcified crust. The anthropological study was restricted in its scope by the bone condition and the analysis thus focused on the identification of the individuals and the burial practices.

\subsection{Minimum number of individuals}

When human skeletal remains are intermixed in a grave, the exact number of individuals forming the assemblage cannot be known with any certainty. Theoretically, each separate bone could originate from a different individual, either as a result of disarticulated body parts being introduced into the grave as secondary deposits, or because after a body had been buried, complete bones were lost through deliberate removal, robbing, erosion, destruction, incomplete excavation, poor preservation, high fragmentation, and identification problems (Poplin, 1976; Masset and Sellier, 1990; Mays, 1998). This extreme situation is unlikely in most funerary contexts. Having assessed other

\footnotetext{
1 The human remains from Azraq 18 are currently housed at the Council for British Research in the Levant (CBRL) in Amman.

2 This information was extracted from an unpublished preliminary report written by S. Bourke who recommended more detailed laboratory work in the future.
} 


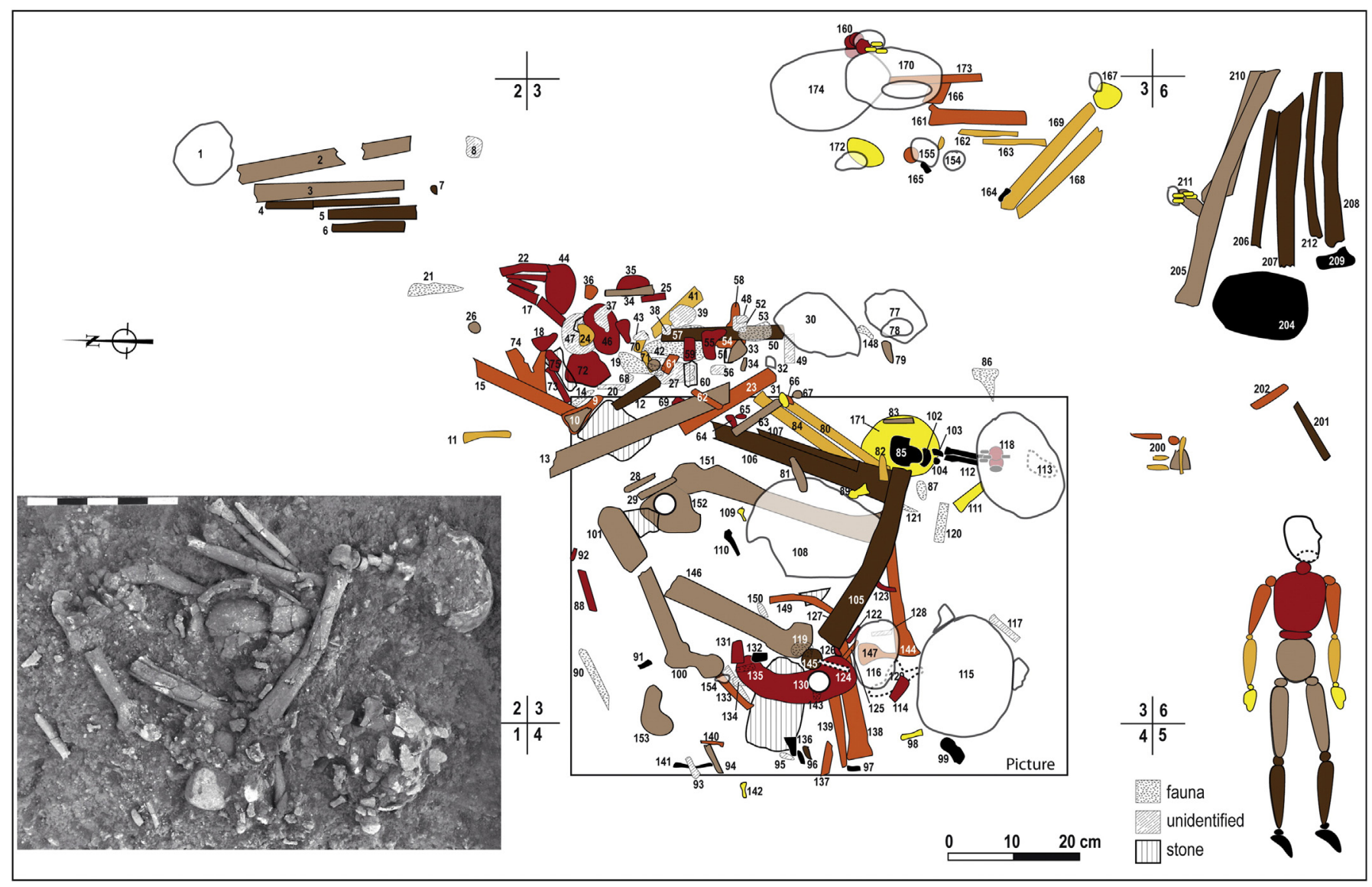

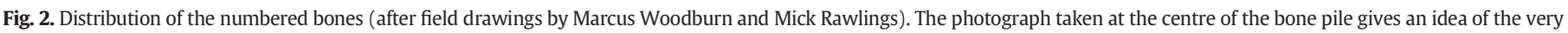

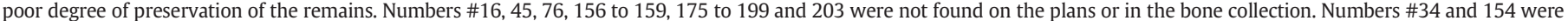
attributed twice.

possible approaches (see for instance Rogers, 2000; Adams and Konigsberg, 2004), we chose to estimate the Minimum Number of Individuals that contributed to the sample, and believe this is the only way to provide reliable data for a funerary interpretation. Three steps were followed for calculating the MNI. First, we counted the frequency of diagnostic "landmark" bones (or fragments of bone) present in the assemblage. The right humerus gave the best result with a MNI of seven individuals (four immature individuals and three adults). Secondly, we sought to determine if there could have been more skeletons by looking for possible individuals that were not represented by the right humerus, designated as "MNI by isolation" (Poplin, 1976). We started by looking for matching pairs in the case of pairs of bones or broken axial bones. Bones were organised into three groups according to the results: "definite paired elements", "undetermined elements" and "definite isolated elements". Only this last category of isolated elements was used in order to expand the MNI. Thus the MNI calculated by element is:

\section{Max Left OR Max Right + Isolated Left + Isolated Right.}

In the case of Azraq 18, the corpus is small and only a few isolated elements of this type were found amongst the different categories of paired bones (or broken axial bones). In relation to the humerus, no isolated elements were found, and the MNI was consequently not increased. The principle of isolation was then applied to the whole collection (Poplin, 1976). In the present case, individuals that were not represented by the right or the left humerus were selected. Criteria for associating or excluding elements was based on robustness or specific pathology, but the most helpful was age determination. This procedure increased the MNI of immature individuals by one. At the same time, the comparison of the whole collection led to the conclusion that only three adults were present in the recovered assemblage: two gracile individuals and one robust one, all being relatively well represented. The homogeneity amongst the different categories of mature bones, and the fact that many are matching pairs, argues in favour of a MNI close to or identical with the Real Number of Individuals for the adults. According to the coxal morphology, one of the gracile skeletons might be a male (Bruzek, 2002), although it was only partially preserved. The two other Os coxae are too damaged for sex determination. With regard to the age-at-death of the adults, nothing can be said except that bone maturation was complete (iliac crests fused; but the medial extremity of the clavicles, pubis and auricular surfaces of the ilium were unobservable). Finally, the third step consisted of evaluating whether the bone associations determined in the laboratory matched those observed in their spatial arrangement in the excavated deposits. This demonstrated that bones showing preserved anatomical connections in the grave had been attributed to the same individuals as those determined using biological criteria in the laboratory (see also Sections 2.4.1 and 2.4.2).

In summary, out of the 320 fragments of bones recovered from the Azraq 18 grave, eight individuals can be identified: five immature individuals and three adults (Table 1 ). While considering that a complete skeleton is composed of a minimum of 206 bones (many more for an immature specimen), the degree of representation of the Azraq 18 skeletons appears extremely poor. Indeed, the nature of the funerary deposition, whether resulting from the burial of intact bodies or the burial of selected bone remains, can be debated. However, the fact that all categories of bones are represented, from very small to large 


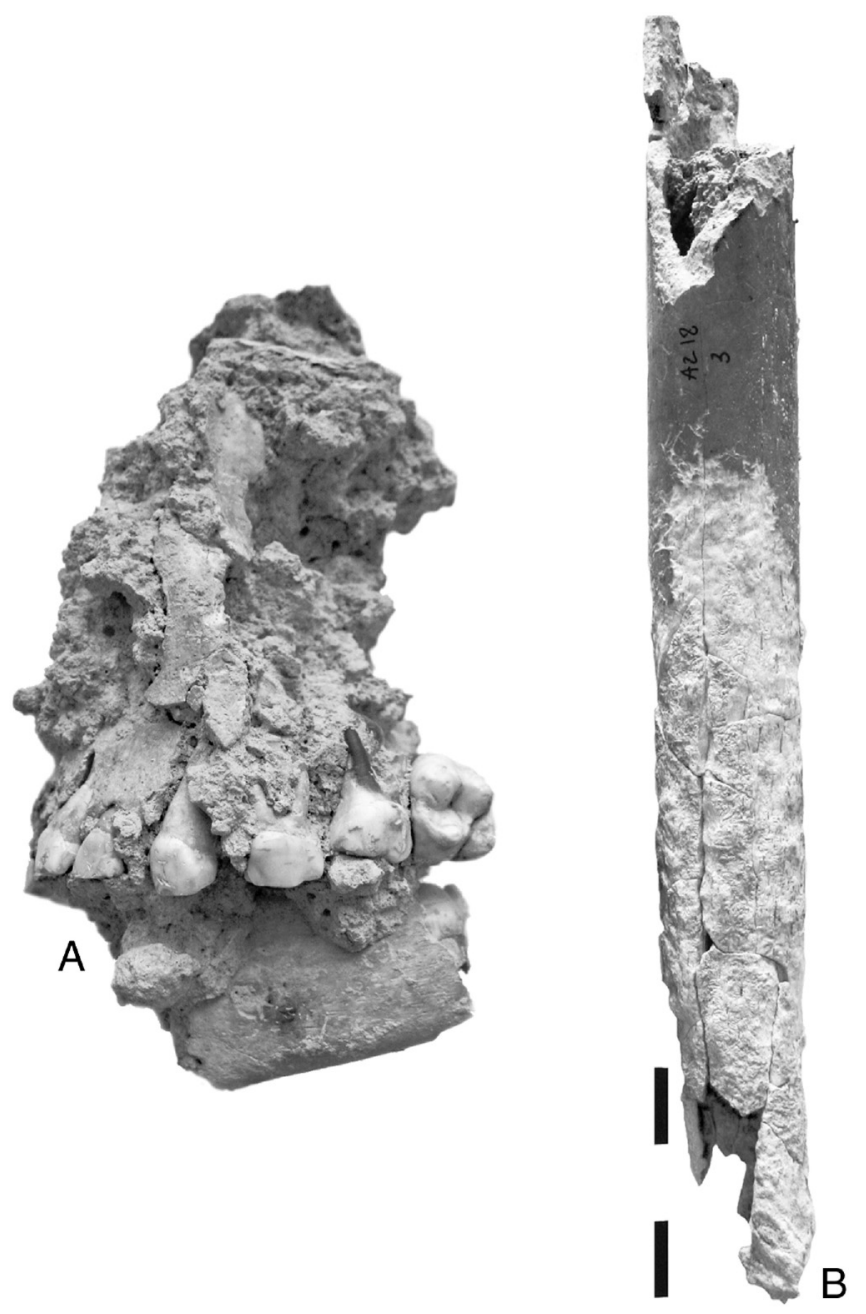

Fig. 3. Illustration of the poor preservation of the bones. A: \#113: left maxilla and fragment of mandible of Individual E crushed in situ and heavily encrusted. B: \#3: Diaphysis of right femur of individual D showing erosion of the bone surface.

Table 1

Age at death of the immature elements was estimated according to Scheuer and Black (2000) for the bones and Moorrees et al. (1963a and b) for the dental remains. The metric and dental mineralisation data were also compared to the rest of the Natufian immature population (Bocquentin, 2003). Specific elements are indicated when a unique number was attributed to more than one bone in the excavation.

\begin{tabular}{|c|c|c|}
\hline Individuals & Identification & Bone attribution \\
\hline A & Robust mature adult & $\begin{array}{l}\# 15,139,165,167,168,169,204,205,206, \\
207,208,209,210,211,212\end{array}$ \\
\hline B & Mature adult, male? & $\begin{array}{l}17,18,22,23,24,25,35,40,41,70,71,75,85 \\
100,101,102,103,104,105,106,107,110 \\
112,146,151,152\end{array}$ \\
\hline C & Mature adult & $10,13,24,31,57,80,84,144,171$ \\
\hline $\mathrm{D}$ & $\begin{array}{l}\text { Adolescent } \\
\text { (10-15 years old) }\end{array}$ & $\begin{array}{l}1,2,3,4,5,6,7,36,44,46,54,58,73,160 \\
161,166\end{array}$ \\
\hline E & 4-6 years old & $\begin{array}{l}\text { 78, 113, 118, 162, 163, 172, } 200 \text { (humerus), } \\
201 \text { (tibia), } 202 \text { (humerus) }\end{array}$ \\
\hline $\mathrm{F}^{\mathrm{a}}$ & $3-5$ years old & $\begin{array}{l}82 \text { (radius), } 140 \text { (humerus), } 200 \text { (ulna, radius), } \\
118,154,155\end{array}$ \\
\hline G & $0.5-1$ year old & $94,116,123,125,126,130$ \\
\hline $\mathrm{H}$ & Perinatal & $\begin{array}{l}81,124 \text { (isolated tooth buds), unmapped } \\
\text { femur, ulna, vertebrae }\end{array}$ \\
\hline
\end{tabular}

a The bones attributed to individual $\mathrm{F}$ might, in fact, be the remains of two different children, one represented by post-cranial bones only and aged about 2-3 years at death and the second represented by a cranium only and aged by the teeth to about $3-$ 5 years old at death. The overlapping ages and the fact that the sets of bones complement each other and that dental and individual elements might not develop at the same rate due to stress during growth and development, leads to a conservative estimate and a suggested MNI of 1 individual. pieces, makes the second hypothesis less likely (e.g. Chambon, 2003). The spatial distribution of the bones provides the most suitable data for determining this issue.

\subsection{Funerary treatment in 4D: bone distribution and dynamics}

At first, this assemblage of human remains might appear hard to interpret. However, from close analysis it is clear that this bone pile, which resulted from various stages in the funerary handling of the dead, is not distributed in a haphazard fashion. Although the original cultural or ritual significance of the funerary deposition may be lost, the physical remains were investigated in order to determine the extent to which their distribution and condition resulted from burial or post-burial factors. Indeed, a careful examination of the different skeletal elements, their spatial distribution and relation to each other has made possible a number of inferences (for major contributions in this field see Leroi-Gourhan et al., 1962; Duday and Masset, 1987; Chambon, 2003). The analysis was undertaken step-by-step with the objective of going back in time from the final spatial distribution of the remains as seen during the excavation process, to the initial establishment of the grave.

\subsubsection{First level of analysis: how is the bone pile organised?}

An overview of the spatial distribution of the bones according to anatomical segments gave the impression of disorder except at the periphery of the grave which looked, from the outset, more organised (Fig. 2). There was an anatomical sequence of feet $(\# 204,209)$ and lower limbs (\#205-208, 210, 212) at the south-east corner of the distribution area.

\subsubsection{The search for anatomical connections}

Potential evidence of preserved articulated joints was available from several sources: the excavation photograph (Fig. 2), specific comments made in the field notes, encrusted anatomical blocks present in the bone collection, and the field plans. However, laboratory analysis was required to confirm that the perceived articulated bones were indeed part of the same skeleton. Several coherent anatomical clusters could be identified, suggesting that the bone pile showed some kind of organization. None of them were strictly anatomically connected, but they were close enough to indicate that, aside from the impact of gravity during the decay process, no further displacements had occurred. We might refer to these clusters as "loose" articulated joints (Leclerc, 1975: 20). These clusters included segments of vertebral column, tibiae and fibulae and foot bones, humeri and scapulae, hand bones, complete femora, crania and mandibles and crania and first cervical vertebrae (Fig. 4). Amongst these, it should be noted that there were labile joints like those of the hands, feet, rib cage and shoulder, which are known to disarticulate quickly after death; perhaps within a few weeks at the most. They are positive indicators of primary burials, which means that the corpse was placed in the grave soon after death. However, while some anatomical segments remained in their initial location, others were disarticulated and amongst them were labile as well as more durable (or persistent) articulations. This demonstrates that more major disturbances occurred, some having happened late in the decay process. As some preserved articulations were lying on top of disarticulated joints, one may surmise that there was a succession of burials and that some of the disturbances were likely to have resulted from the repeated nature of funerary rites in this locality.

2.4.1.2. Anatomical disarticulations: what they teach us. The process of refitting and matching pairs of related bones helped us to reconstruct some of the secondary movements which were previously suspected. This process permitted determination of the movements of skeletal elements across the entire area of the grave (Fig. 4). Thus, although the limits of the pit were not visible during excavation, the unearthed remains appeared to be part of the same assemblage: the dead were buried in the same grave and shared the same space during their 


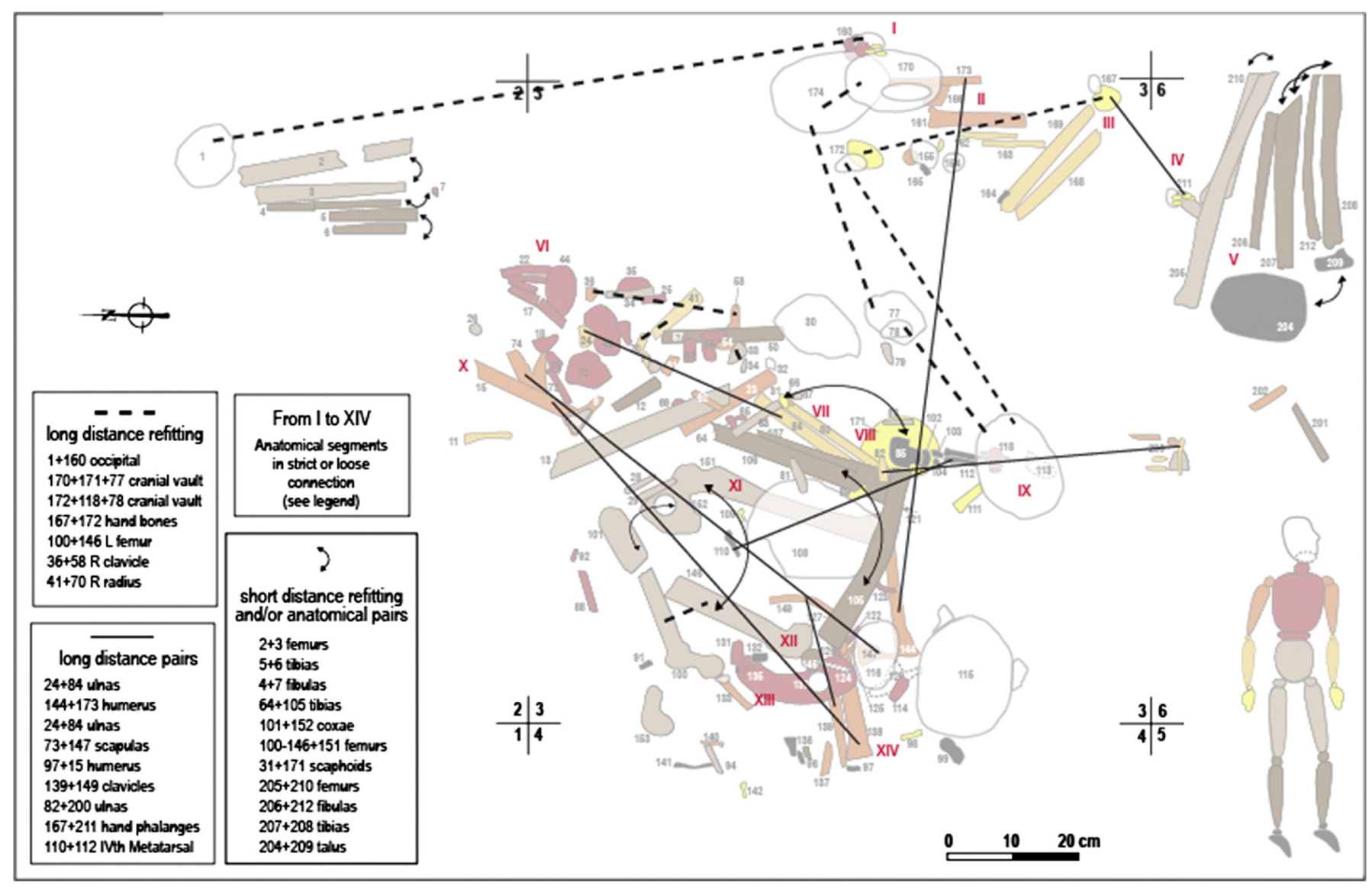

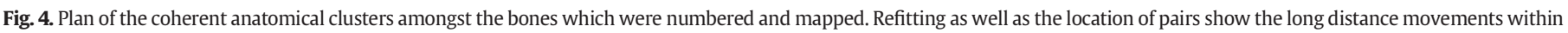

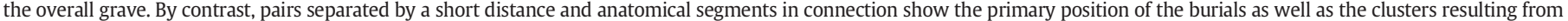

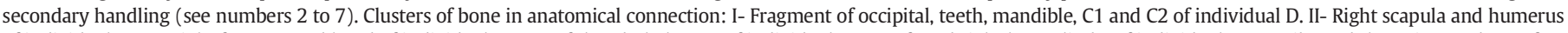

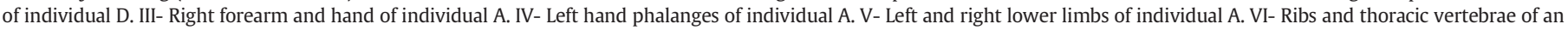

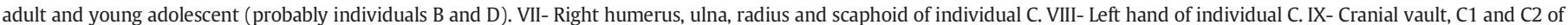

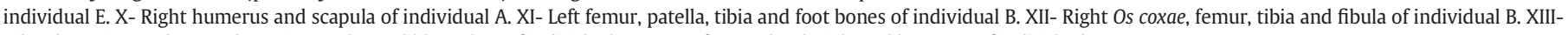
Ribs, thoracic vertebrae and cranium and mandible and C1 of individual G. XIV: Left scapula, clavicle and humerus of individual A.

decomposition. A second observation is that the larger movements were mainly restricted to crania and upper limb bones.

\subsubsection{Second level of analysis: who's who?}

A second level of analysis attempted to reconstruct each skeleton according to the spatial distribution, robustness and maturity of the bones. Concerning the adults, the remains of the most robust skeleton (Individual A) could be located without major difficulty. The integrity of the skeleton was preserved in great part at the southeast corner of the grave while its humeri, clavicles and scapulae were scattered at the bottom of the bone cluster found in the centre of the grave (Fig. 5). Meanwhile, left and right shoulders had moved as independent clusters. This skeleton must have been the first adult buried, lying on its left side, lower limbs tightly flexed. The two other adults are about the same size and their remains are intermixed, resulting in them being only partially identified. The spatial distribution of articulated joints, as well as matching pairs of bones, played an important role in their identification (Fig. 4). On top of the pile, the skeletal remains identified as individual $\mathrm{B}$ indicated that the body was likely to have been lying on its chest (i.e. prone), with the right lower leg flexed against the thigh while the left one, partially flexed, crossed the right knee. The ribs, vertebrae, as well as the forearm, which were thought to relate to this person, were located further to the northeast following the main axis of the pelvis. The third adult, individual C, was most probably buried following an opposite orientation, with the cephalic extremity oriented towards the southwest. This is supported by the position of the complete articulated upper right limb, as well as the matching left hand, which was found near the right knee. Taking into account that the left femur and tibia were not recovered, it seems likely that this last individual must have been deposited before individual $\mathrm{B}$, and was lying on its right side in a semi-flexed position. It is worth noting that the left humerus matching with the undisturbed right humerus was found far away, close to the northern limit of the grave (Fig. 5).

Regarding the children, the spatial analysis is more difficult as they are more numerous and less well preserved (Fig. 5). Despite this, it seems that individual $G$ (a baby that died before it reached the age of one year) for whom the bones are still clustered, was found close to its initial burial location. Only a few of the bones of a foetus/neonate ${ }^{3}$ (individual $\mathrm{H}$ ) were precisely mapped, but all of them were found in the north-west quarter of square 3 . This is the area of the abdomen of both gracile adults, and it is possible that it may have been a foetus within the belly of its mother when buried. The bones of individuals $\mathrm{E}$ and $\mathrm{F}$ are too few and scattered throughout the grave to be conclusively interpreted. The articulated cranium, mandible and two superior-most cervical vertebrae of individual $\mathrm{E}$, which were next to the left foot of individual B, might represent a primary location or a secondary displacement. Lastly, individual D was better documented. Its remains were clustered into three main groups. The first was found next to individual $\mathrm{A}$ at the eastern edge of the burial and the cluster includes small bones,

\footnotetext{
${ }^{3}$ Exact determination was not possible.
} 


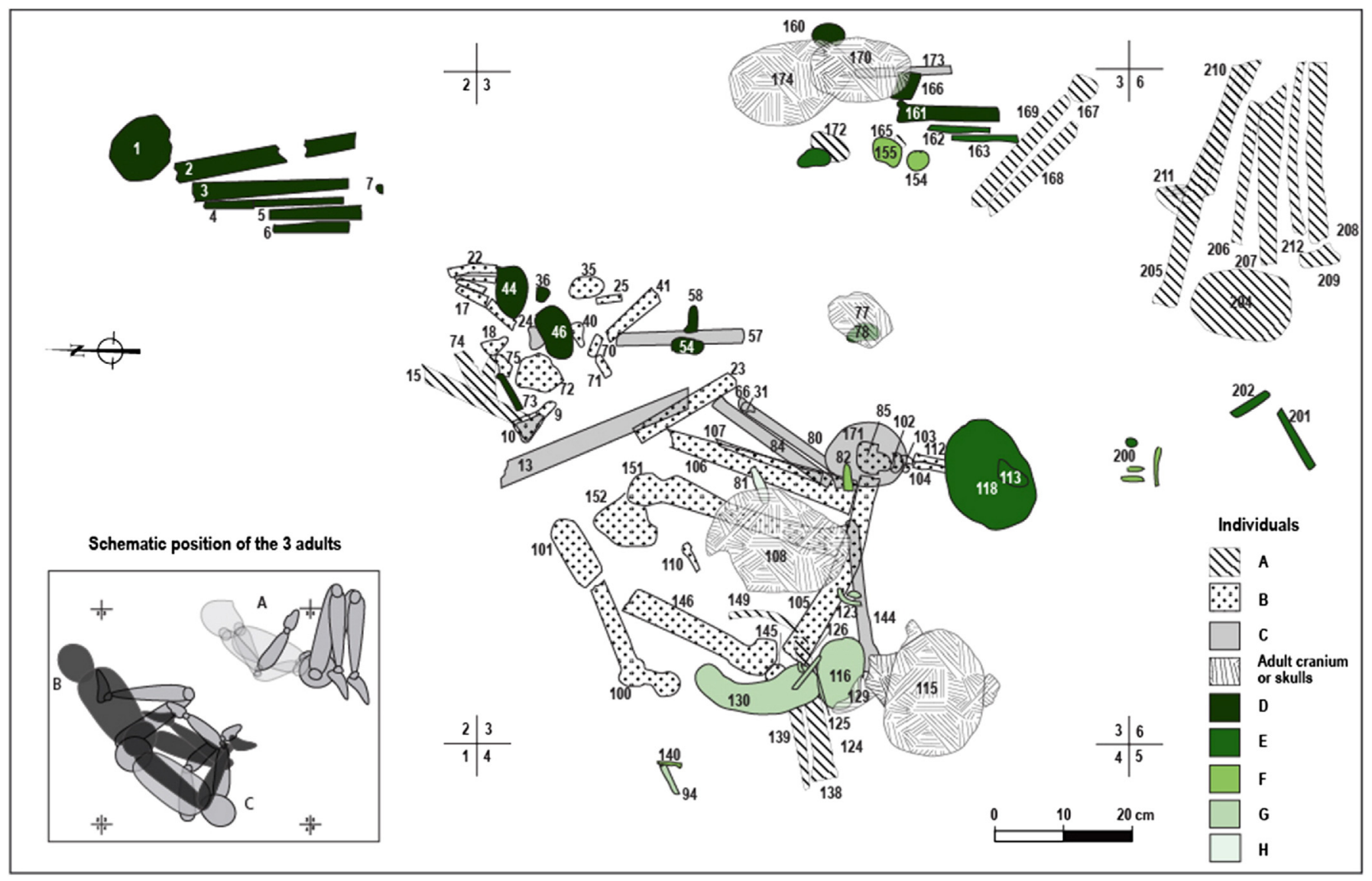

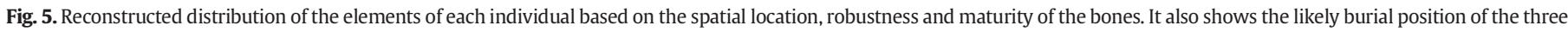
adults.

pieces of cranium, mandible, and a first cervical vertebra, as well as an articulated segment of the upper right limb. A second cluster, mainly of vertebrae and ribs, was found mixed with the axial remains of individual B. A third cluster is found at the north edge of the pit and consists of disarticulated long bones and a fragment of frontal bone. Altogether, it seems likely that the adolescent was buried at the eastern part of the grave and was later partly removed and placed further north. This secondary handling may be connected to the burial of individual A, possibly due to the need for additional burial space.

The successive nature of the burials is confirmed by the fact that the individuals partly overlap each other and also by the major disturbance which each new burial made to the preceding ones. The distance of movement of some clusters of bones strongly suggests secondary handling in order to free additional space for the next cadaver, but it may also have been as part of a ritual act. Indeed, the displacement of some isolated or clustered bones does not always seem to have been for practical reasons. In terms of the sequence of burials, one can reasonably suggest that Individual $\mathrm{D}$, and then $\mathrm{A}$, were buried first, followed by $C$, after which $B$ and $G$ were likely to have been the last to be buried. It is difficult to establish the relative timing of the burial of the immature individuals $\mathrm{E}, \mathrm{F}$ and $\mathrm{H}$ versus the others. The timing between the different burials must have been long enough for the previous corpses to have skeletonised and the major joints to have become disarticulated.

\subsubsection{The specific issue of crania}

Anatomical criteria do not help much in matching the remains of the cephalic extremity to post-cranial remains, especially in the case of Azraq 18 where the bones are very poorly preserved and crushed. Two of the crania were found in close proximity to their mandibles, but whether the temporo-mandibular joints were articulated or not was not recorded. The third cranium (108) was found without its mandible. None of them were articulated to cervical vertebrae. According to their spatial distribution and the suggested burial position of the three adults, one could attribute cranium 115 to individual $C$ and cranium 170-174 (refitted bone) to individual A (Fig. 5). However, the identity of cranium 108 which was discovered wedged between the articulated lower limbs of individual B is uncertain. Indeed, if this third cranium comprises the remains of the head of individual B, how can it be located between its lower limbs? If this was a result of the secondary handling of the cranium, then we should also observe secondary displacements of the lower limbs, including the disarticulation of the foot, the joints of which are labile ones. Another possibility is that this individual was decapitated and the cephalic extremity placed between the lower limbs at the time of burial. The poor state of preservation of the bones did not permit identification of possible cut-marks which would support this act, so this cannot be accepted as evidence of decapitation. Moreover, pre-burial removal of the cephalic extremity is unknown in Natufian contexts and is de facto an unlikely hypothesis. A third possible explanation is that cranium 108 does not belong to individual B but rather to individuals $A$ or $C$, which were previously buried. The burial of individual $B$ could have been undertaken at the same time as the removal of the mostly decomposed cranium and mandible of either individual A or C, which could then have been placed in close contact with the new cadaver. Overall, the identity of the cranium belonging to individual B remains unsolved. Definitely, it is not located where one would expect it, and it has clearly been displaced. Displacements of crania in collective Natufian burials are a well-established pattern (Bocquentin, 2003). They are usually pushed to the periphery of the burial pit suggesting a need for more burial space. In the present case, this simple practical explanation does not seem to fit as even the cranium of the last individual buried was moved. 


\subsection{Traces of pigments on two crania}

A feature of particular interest was the presence of pigmented areas on some of the adult cranial remains. Some traces were already noticed during the fieldwork and reported in the preliminary publication: "This robust male had ochre pigment on his cranium [\#170-174], demonstrating that it was defleshed at the time of burial" (Garrard, 1991: 240 ). The traces of pigments are light but indeed of major importance as they are one of the oldest occurrences of deliberately pigmented human remains in the Near East (see also Webb and Edwards, 2002, 2013). They are found, in fact, on two crania: $170-174$ and 108 (Figs. 6 and 7), and might provide evidence for the first modification of human crania which would become an important aspect of burial practices in the subsequent Neolithic of the southern Levant.

\subsubsection{Pigments on cranium 108}

Red pigment is found all over the preserved bones of cranium 108: the left maxilla and zygomatic, the frontal, both parietals, the left mastoid and a left piece of the occipital. It not only covers their ectocranial surface, but also penetrates the unfused sutures as well. No specific pattern is observed, except that the pigment is only preserved in depressions or rough anatomical areas. The colour is particularly bright where breccia, which had been stuck to the bone, was removed in the laboratory (Fig. 6A). Concerning the bones of the face, the pigment covers the anterior and lateral surfaces but neither the inferior nor the posterior ones. On the zygomatic, the pigmented area includes the orbital surface. On the maxilla, the pigment is dense on the anterior edge of the alveolar process, and it also covers the single preserved tooth (M1). The other alveoli are either broken or filled by unpigmented calcrete (Fig. 6B). The vault also shows traces of red pigment all over the ectocranial surface of the preserved bones. It is mainly found next to the sutures and follows the anatomical traps created by notches, foramina, crests, grooves, margins and lines of muscle attachments (Fig. 6C). It is worth noting that the preserved orbital parts of the frontal do not show any pigmentation, in contrast to the zygomatic bone. In the metopic area of the frontal, the pigment is quite thick. The red pigment is also well attested on both parietals in the sagittal, pterion and lambdoid areas and follows the temporal lines. The red pigmentation of the occipital is lighter, still preserved on the inferior nuchal line and in the area of the asterion. The preserved portion of the left temporal is pigmented along the same edge.

\subsubsection{Stains on cranium $170-174$}

In the case of cranium 170-174, three different materials were thought to be present as three different coloured residues were noted. The facial bones are not preserved and the main concentrations of
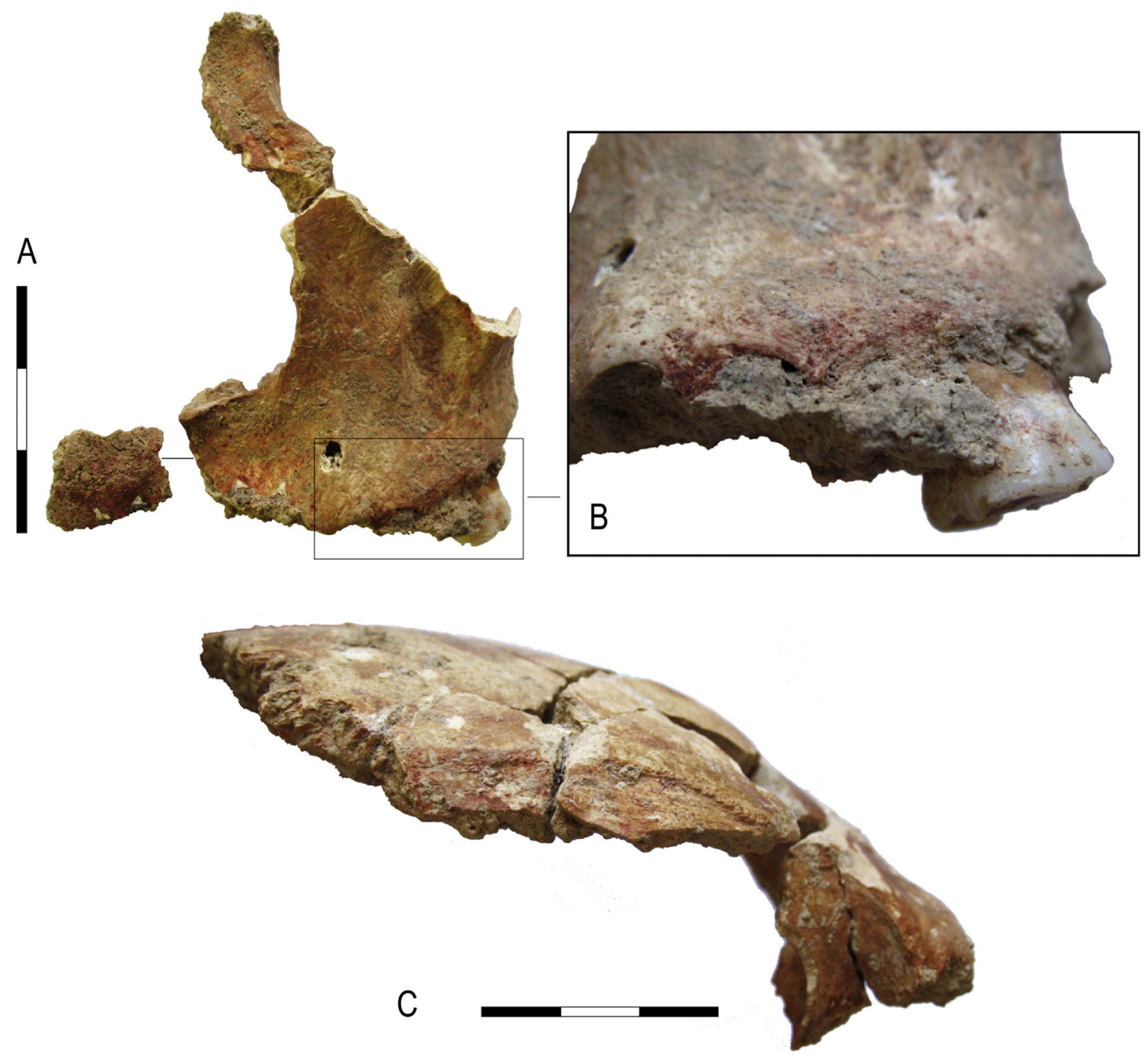

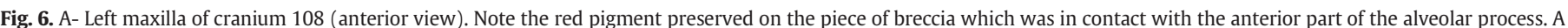

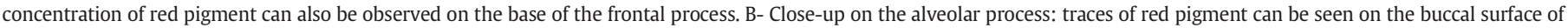

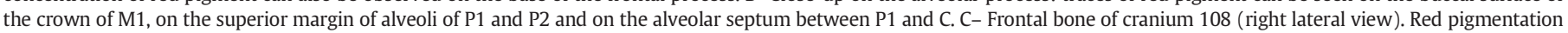

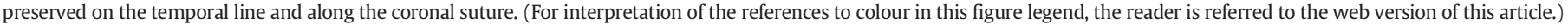




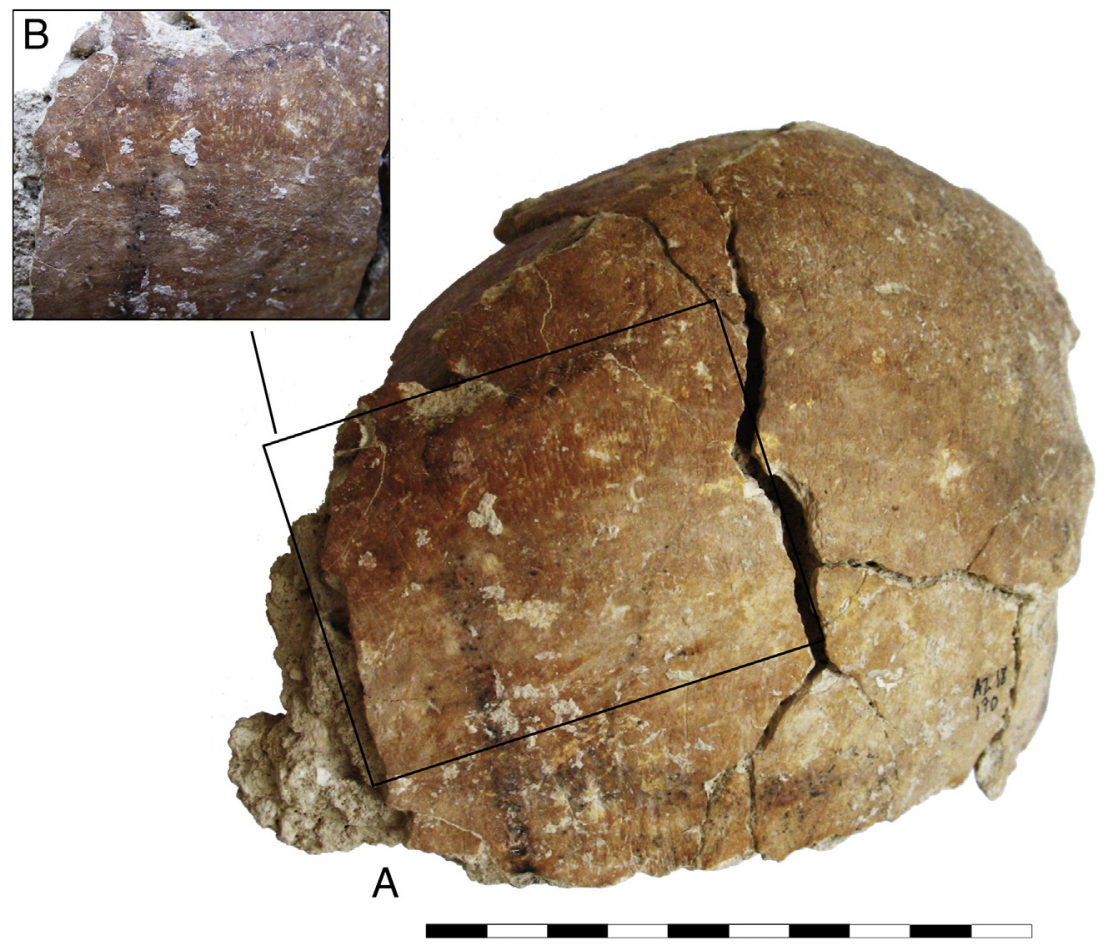

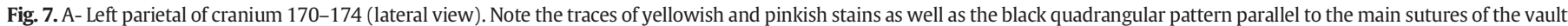

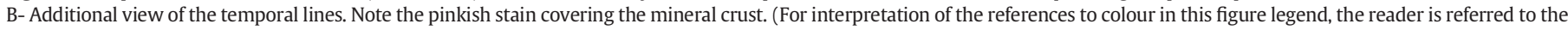
web version of this article.)

pigment are found on the occipital, and mainly on the right side of the squamous area. The pigment, which is less bright than in the case of 108 , appears pinkish. The same pigment is found as well on the portion of preserved frontal bone, and sparsely on both parietals and the right temporal. This is, again, mainly in the anatomically rough areas of the cranium (Fig. 7A). In addition to this pinkish pigment, a yellowish stain on the vault, especially on the occipital and the left parietal, might be an artificial colouring or a pre-treatment. Unlike the red pigment, no distinct limits can be observed. Finally, worth noting are the impressive black stripes on the frontal, parietals and right temporal organised according to a quadrangular pattern following the natural curves of the vault. It is not clear if these are the remains of manganese pigment directly applied to the cranium, or the residue of a decomposed organic material or bitumen. The relative chronology of the application of these different materials is most interesting. The yellow staining is covered by the pink pigment which in turn is covered by the black residue. All of them were subsequently covered by a thin calcified crust. A second layer of pinkish pigment was then applied on top of the mineral crust, sometimes filling some cracks in the bone (Fig. 7B). This, in turn, was later covered by a second calcareous crust.

\subsubsection{Summary of the cranial pigmentation}

The pigmentation covers the vaults and the facial bones when preserved. The bases of the crania are poorly preserved, but the areas present do not show any traces of pigmentation. It is unlikely that the cranial bases or the mandibles were pigmented. The residues are too limited to provide any indication of the application technique and no obvious trace of brush strokes was noticed. The chemical composition of the pigments is still to be determined, but from laboratory work it appears that the red pigment is photosensitive.

Although we evaluated whether the pigmentation may relate to the initial burial treatment (corpse or head decoration or staining of shroud or burial clothes), an array of evidence points to the direct application of pigment to the cranial surface after the flesh had disappeared. First of all, there is a sharp contrast between these two pigmented crania and their immediate environment. The red pigment was identified in the field because the surrounding sediment was totally different. Moreover, they are the sole skeletal remains to be coloured, even the adjacent mandibles show no traces of pigment. Second, in the case of cranium 108 , the zygomatic area shows the greatest concentration of pigment, despite the fact that this would have been covered by thicker flesh. Third, the fact that red pigment is present in the lateral part of the left orbit of 108 also demonstrates that it was applied after the decomposition process. The absence of pigments on the rest of the orbit might indicate that a modelled eye was placed in the orbit before staining. However, the most convincing observation is that the two layers of pinkish staining on specimens 170-174 are each followed by an episode during which a calcareous crust formed on the surface suggesting reburial between applications of pigments. Altogether, there is no doubt that the colouring process is part of a secondary handling of the dead. These two crania were removed after the decay process, pigment applied and then replaced in the grave. Were they immediately replaced within the grave, or did they spend a period of time in the world of the living and perhaps were they used as ceremonial objects? Is this treatment only part of the funerary handling, or did it involve further commemoration? These questions remain open and maybe other similar discoveries on much better preserved remains will provide further clues to help with interpretation. Meanwhile, it is important to note that this treatment of crania, which involved several stages, including the application of pigments, is previously unknown in a Natufian context. ${ }^{4}$

\section{Results and discussion}

At least three adults and four children (from newborn to young adolescent) were deposited over time in the grave discovered at Azraq 18. A majority, if not all, of the burials were successive and each re-opening

\footnotetext{
${ }^{4}$ However, red pigmentation was mentioned on post-cranial bones at Wadi Hammeh 27 (Webb and Edwards, 2002: 109, 116; Webb and Edwards, 2013: 380-381)
} 
of the grave resulted in the displacement of the bones of the previous decayed cadavers. No initial organization according to age was detected and the remains of all individuals eventually became commingled. This is due to two main factors: 1 ) according to the archaeothanatological analysis (see for instance: Chambon, 2003; Duday, 2009; Knüsel, 2014), the decay process of the cadavers occurred within an empty space which has permitted significant movement of the bones; 2) secondary handling of the remains recurred but with no apparent standard pattern. Does this pattern have a technical/practical origin (e.g. relating to creating space) and/or does it also have a funerary/ritual meaning? What we can argue is that all skeletons were moved, including the last one that was deposited. Therefore a simple practical reason does not explain all the observed displacements. The high level of fragmentation of the remains, which occurred before mineralisation, may indicate that no special attention was given to the post-cranial bones, which were not the focus of secondary manipulation.

The burial positions of the children are unknown. However, the two adults were deposited on their sides (one left, one right) with their limbs flexed, which is one of the most common burial positions for the Natufian. By contrast, the third adult seems to be lying on its abdomen (i.e. prone), a position which is much less frequent ( $7 \%$ of Natufian skeletons: Bocquentin, 2003: 313).

The adult crania show a remarkable series of treatments which involved several steps, including removal, displacement, application of pigments, re-application of pigments and reburial. Traces of pigmentation are poorly preserved but undeniable on two of them. The application coloured pigments was made directly on the face and ectocranial surface of the cranial vault. The orbits and base, left unpigmented, might have been inaccessible during the colouring process or purposefully avoided. They may have been covered by perishable materials (e.g. modelled eyes and there may have been a base into which the cranium was inserted). In one case three potential different materials, of yellow, red and black colour, were superimposed. The black material appears to be arranged in stripes, the arrangement of which might be the result of an imprint of organic residue or the result of purposefully painted lines. In any case, this pattern is reminiscent of the modified 8th millennium crania from the southern Levant.

It is likely that the complex manipulation of crania in Neolithic contexts, from removal to remodelling and painting, may find its roots deep within Natufian traditions (e.g. Kuijt, 1996). Nevertheless, even though at many sites the poor preservation of Natufian bones (frequently encrusted) may have disguised any traces of staining, it is most likely that the practices observed at Azraq 18 were an exceptional phenomenon. That being said, the practice of complete skull or cranial removal, in itself, is well documented. From the beginnings of the Early Natufian, a few skulls or crania are found isolated from infracranial remains (for example at Erq-el-Ahmar and Eynan-Mallaha). Grave Via in Hayonim Cave, with an MNI of 15 individuals and a clear deficit of cranial remains, could represent one of the earliest direct examples of skull (crania and mandibles) removal (Bar-Yosef and Goren, 1973: 53; Bocquentin, 2003: 201). In this collective grave, complete skulls may have been removed successively at the times when fresh interments were being made. During the Late Natufian, cranium and skull removals are attested for the first time in the record from primary single grave contexts (Belfer-Cohen, 1988; Noy, 1989; Weintsein-Evron, 2009). This means that these graves were re-opened specially, in order to remove elements of the cephalic extremity. It does not appear to have been an opportunistic practice, but had clearly been planned from the time of primary burial. It is likely that the position of the skull was marked, as disturbances to the skeleton are minor, even though most of the individuals concerned were buried directly in the soil rather than in a structure or container that would have facilitated removal (Bocquentin, 2003: 319). Thus it can be considered as part of the funerary protocol, planned in advance and a standard procedure. Cranial/skull removal continues to be practiced through later periods in the southern Levant ;until, during the Middle and Late PPNB, it involves more than a third of the dead
(Bocquentin et al., forthcoming). This increase is contemporaneous with the appearance of the dramatic custom of cranium (and later skull) remodelling (elements of discussion and references e.g.: Kuijt, 1996; Croucher, 2006; Bonogofsky, 2011; Khawam, 2014). Although still present, there was a major decline in manipulation of the cephalic extremity during the later Neolithic (7th millennium BC).

Many graves identified as "collective" in the Natufian context are actually clusters of single graves which are so close together that they disturb previous graves. Post-depositional disturbances which include the scattering and re-grouping of bones can give the impression of collective handling. With the exception of a notable "collective burial phenomenon" in the Late Natufian of Eynan-Mallaha (Perrot and Ladiray, 1988; Bocquentin, 2003), primary successive Natufian burials are scarce, however. The Azraq 18 grave, attributed to the end of the Early Natufian, could be one of the earliest structures of this type (the other being grave Via at Hayonim Cave).

Overall, collective burial treatment during the Natufian is well attested, but the management of these complex graves and the funerary behaviours associated with them are poorly understood. This can be explained by the specific difficulties of digging and interpreting these structures: skeletons are commingled, partially or fully disarticulated, and the bones are heavily fragmented. The understanding of the burial treatment cannot be determined immediately but requires several steps in their study and a detailed recording at various scales to clearly represent the state of the remains, for which success will depend on the quality of the field records (e.g.: Duday et al., 1990). The position of each bone, their anatomical relationships, and the degree of articulation are indispensable data which will help to identify individuals from the collective pile of bones, determine the movement in the bones, and reconstruct the dynamics of the burial process and the subsequent manipulations over time. Although the bones from Azraq 18 were poorly preserved, the mapping and numbering of almost all the bones has permitted a depth of analysis incomparable with the other Natufian collective graves dug in the 1960s and 70s. It is hoped that future excavations will provide comparable archaeological documentation which will enable a better understanding of the nature of the primary depositions, their secondary handling, and of the possible removal of bones.

\section{Conclusion}

The collective grave from Azraq 18 provides an important testimony to the complex funerary management of the dead and to subsequent bone manipulation during a period dating to the later stages of the Early Natufian. Although poorly preserved, this small anthropological collection has permitted determination of the position at burial, secondary manipulations of the bones, and the specific treatment of crania which had been removed, had pigment applied and were replaced in the grave. This study provides new insights into the collective handling of the dead during the Natufian and will help in the interpretation of future discoveries. It also provides the opportunity to place the funerary treatment observed at Azraq into its wider context. The changes in mortuary practice witnessed in the Natufian are a process which runs in parallel with the coalescence of people into long-term residential groups.

\section{Acknowledgements}

We are especially grateful to Pr. Christopher Knüsel and Pr. John Robb for inviting us to participate in this special volume and for their comments and corrections which have helped us greatly with the improvement of this paper. AG would like to thank the Department of Antiquities in Jordan for the permission he received to undertake the 1985 excavations at Azraq 18 and for the support he received from the British Institute at Amman for Archaeology and History. The original study of the skeletal material was undertaken by Stephen Bourke (University of Sydney), and we would like to thank him for access to his unpublished notes on the analysis. The British Institute at Amman (CBRL) 
houses the anthropological collection and FB is grateful to Bill Finlayson for his warm welcome while undertaking the lab-work and to the Department of Antiquities for permission to export a small quantity of material for study in Paris and London. We would like to thank Danièle Molez for assistance with Fig. 2.

\section{References}

Adams, B.J., Konigsberg, L.W., 2004. Estimation of the most likely number of individuals from commingled human skeletal remains. Am. J. Phys. Anthropol. 125 (2), 138-151.

Bar-Yosef, O., 2002. Natufian. A complex society of Foragers. In: Fitzhugh, B., Habu, J. (Eds.), Beyond Foraging and Collecting. Evolutionary Change in Hunter-Gatherer Settlement Systems. Kluwer Academic/Plenum Publishers, New York, pp. 91-149.

Bar-Yosef, O., Goren, N., 1973. Natufian remains in Hayonim cave. Paléorient 1, 49-68.

Belfer-Cohen, A., 1988. The Natufian graveyard in Hayonim cave. Paléorient 14, 297-308.

Bocquentin, F., 2003. Pratiques funéraires, paramètres biologiques et identités culturelles au Natoufien: une analyse archéo-anthropologique. Thèse de Doctorat en Anthropologie Biologique. Université Bordeaux 1, Talence (unpublished). http:// 147.210.235.3/proprietes.html?numero ordre $=2769$.

Bocquentin, F., Chambon, P., Le Goff, I., Leclerc, J., Paria, J.-G., Pereira, G., Thevenet, C., Valentin, F., 2010. De la récurrence à la norme: interpréter les pratiques funéraires en préhistoire. B. Mem. Soc. Anthro. Par 22, 157-171.

Bocquentin, F., Cabellos, T., Samuelian, N., 2013. Graves in context: field anthropology and the investigation of interstratified floors and burials. In: Valla, F., Bar-Yosef, O. (Eds.), Natufian Foragers in the Levant. International Monographs in Prehistory, Ann Arbor, Michigan, pp. 185-192.

Bocquentin, F., Kodas, E., Ortiz, A., 2016. Headless but still eloquent! Acephalous skeletons as witnesses of Pre-Pottery Neolithic North-South Levant connections and disconnections. Paléorient 42 (2) forthcoming.

Bonogofsky, M., 2011. Contextualizing the Human Head: An introduction. In: Bonogofsky, M. (Ed.), The Bioarchaeology of the Human Head: Decapitation, Decoration, and Deformation. University Press of Florida, Gainesville, pp. 1-47.

Bruzek, J., 2002. A method for visual determination of sex, using the human hip bone. Am. J. Phys. Anthropol. 117, 157-168.

Byrd, B.F., 2005. Reassessing the emergence of village life in the near east. J. Archaeol. Res. $13,231-290$

Chambon, P., 2003. Les morts dans les sépultures collectives néolithiques en France: du cadavre aux restes ultimes (XXVe supplément à Gallia Préhistoire). 395 p.

Croucher, K., 2006. Getting ahead: exploring meanings of skulls in the Neolithic Near East. In: Bonogofsky, M. (Ed.), Skull Collection, Modification and DecorationBAR International Series 1589. Archaeopress, Oxford, pp. 29-44.

Dubreuil, L., 2004. Long-term trends in Natufian subsistence: a use wear analysis of ground stone tools. J. Archaeol. Sci. 31, 1613-1629.

Duday, H., 2009. The Archaeology of the Death: Lectures in Archaeothanatology. Oxbow Books, Oxford.

Duday, H., Masset, C. (Eds.), 1987. Anthropologie physique et archéologie. Méthodes d'étude des sépultures. Éditions du CNRS, Paris.

Duday, H., Courtaud, P., Crubezy, E., Sellier, P., Tillier, A.-M., 1990. L'anthropologie de "terrain": reconnaissance et interpretation des gestes funeraires. B. Mem. Soc. Anthro. Par. t.2 (3-4), 26-49.

Fiedel, J.F., 1979. Intra and inter-cultural variability in Mesolithic and Neolithic mortuary practices in the Near East. Unpublished Ph.D. Thesis. University Microfilms International, University of Pennsylvania, Ann Arbor (Unpublished).

Garrard, A., 1991. Natufian Settlement in the Azraq Basin, Eastern Jordan. In: Bar-Yosef, O., Valla, F. (Eds.), The Natufian Culture in the Levant. International Monographs in Prehistory, Ann Arbor, pp. 235-244.

Garrard, A., Byrd, B., 2013. Beyond the Fertile Crescent: Late Palaeolithic and Neolithic Communities of the Jordanian Steppe. The Azraq Basin Project, Volume 1: Project Background and the Late Palaeolithic (Geological Context and Technology). Oxbow Books, Oxford Levant Supplementary Series 13.

Garrod, D.A.E., Bate, D.M.A., 1937. The Stone Age of Mount Carmel. Clarendon Press, Oxford.

Goring-Morris, N., Belfer-Cohen, A., 2010. Different ways of being, different ways of seeing... Changing worldviews in the Near East. In: Finlayson, B., Warren, G. (Eds.), Landscapes in Transition. Oxbow, Oxford, pp. 9-22.

Goring-Morris, N., Hovers, E., Belfer-Cohen, A., 2009. The dynamics of Pleistocene and Early Holocene settlement patterns and human adaptations in the Levant: an overview. In: Shea, J.J., Lieberman, D.E. (Eds.), Transitions in Prehistory: essays in honor of Ofer Bar-Yosef. Oxbow, Oxford, pp. 185-252.
Grosman, L., Munro, N.D., Belfer-Cohen, A., 2008. A 12,000-year-old shaman burial from the southern Levant (Israel). Proc. Natl. Acad. Sci. 105 (46), 17665-17669.

Khawam, R., 2014. L'homme et la mort au PPNB en Syrie: l'exemple de Tell Aswad. Thèse de doctorat. Université de Lyon 2 (unpublished).

Knüsel, C.J., 2014. Crouching in fear: terms of engagement for funerary remains. J. Soc. Archaeol. 14 (1), 26-58.

Kuijt, I., 1996. Negotiating equality through ritual: a consideration of late Natufian and PrePottery Neolithic a period mortuary practices. J. Anthropol. Archaeol. $15,313-336$

Leclerc, J., 1975. Problèmes d'observation et de terminologie à propos de la sépulture collective de la Chaussée-Tirancourt. In: Leroi-Gourhan, A. (Ed.), Séminaire sur les structures d'habitat. Sépultures. Collège de France, Paris, pp. 20-25.

Leclerc, J., Tarrête, J., 1997. Sépulture. In: Leroi-Gourhan, A. (Ed.), Dictionnaire de la Préhistoire. Quadrige, Presses Universitaires de France, Paris, pp. 1002-: 1003 ( $1^{\text {rst }}$ edition: $1988 ; 2$ nd édition: 1994).

Lengyel, G., Nadel, D., Bocquentin, F., 2013. The Natufian at Raqefet Cave. In: Valla, F., BarYosef, O. (Eds.), Natufian Foragers in the Levant. International Monographs in Prehistory, Ann Arbor, Michigan, pp. 478-504.

Leroi-Gourhan, A., Bailloud, G., Brézillon, M., 1962. L'hypogée II des Mournouards (Mesnil-Sur-Oger, Marne). Gallia Préhist. 5, 23-133.

Maher, L.A., Richter, T., Stock, J.T., 2012. The pre-Natufian Epipaleolithic: long-term behavioral trends in the Levant. Evol. Anthropol 21, 69-81.

Martin, L.A., 1994. Hunting and Herding in a Semi-Arid Region: an Archaeozoological and Ethological Study of the Faunal Remains from the Epipalaeolithic and Neolithic of the Eastern Jordanian Steppe Unpublished PhD thesis University of Sheffield.

Masset, C., Sellier, P., 1990. Les anthropologues, les morts et les vivants. Les Nouvelles de l'Archéologie 40, 5-8.

Mays, S., 1998. The Archaeology of Human Bones. Routledge, London.

Moorrees, C.F.A., Fanning, E.A., Hunt Jr., E.E., 1963a. Formation and resorption of three deciduous teeth in children. Am. J. Phys. Anthropol. 21, 205-213.

Moorrees, C.F.A., Fanning, E.A., Hunt Jr., E.E., 1963b. Age variation of formation stages for ten permanent teeth. J. Dent. Res. 42, 1490-1502.

Noy, T., 1989. Some aspects of Natufian mortuary behavior at Nahal-Oren. In: Hershkovitz, I. (Ed.), People and Culture in Change: BAR International Series 508. Archaeopress, Oxford, pp. 53-57.

Perrot, J., Ladiray, D., 1988. Les sépultures. In: Perrot, J., Ladiray, D., Solivérès-Masséi, O. (Eds.), Les hommes de Mallaha, (Eynan) Israël. Paris: Association Paléorient, Cahier du Centre de Recherche Français de Jérusalem 7, pp. 1-106.

Poplin, F., 1976. Remarques théoriques et pratiques sur les unitées utilisées dans les études d'ostéologie quantitative, particulièrement en archéologie préhistorique. IXe Congrès de l'U.I.S.P.P. (Nice, 1976, pré-tirage), Colloque "thèmes spésialisés. Nice: CNRS, pp. 124-: 141.

Richter, T., Arranz, A., House, M., Rafaiah, A.M., Yeomans, L., 2014. Preliminary report on the second season of excavations at Shubayqa 1. NeoLithics 1 (14), 3-10.

Rogers, A.R., 2000. Analysis of bone counts by maximum likelihood. J. Archaeol. Sci. 27, $111-125$.

Scheuer, L., Black, S., 2000. Development and ageing of the juvenile skeleton. In: Cox, M. Mays, S. (Eds.), Human Osteologie in Archaeology and Forensic Science. Greenwich Medical Media, London, pp. 9-22.

Stutz, A.J., Munro, N.D., Bar-Oz, G., 2009. Increasing the resolution of the broad Spectrum revolution in the southern Levantine Epipaleolithic (19-12 ka). J. Hum. Evol. 56, 294-306.

Ubelaker, D.H., 1974. Reconstruction of Demographic Profiles from Ossuary Skeletal Samples. Smithsonian Institution Press, Washington.

Valla, F., Guilaine, J., 2000. La sédentarisation au Proche Orient: La Culture Natoufienne. Premiers Paysans du Monde. Naissance des Agricultures. Editions Errance, Paris, pp. 13-29.

Valla, F., Bocquentin, F., 2008. Les maisons, les vivants, les morts: le cas de Mallaha (Eynan), Israël. In: Córdoba, J.M., Molist, M., Pérez, M.C., Rubio, I., Martínez, S. (Eds.), Proceedings of the 5th International Congress on the Archaeology of the Ancient Near East III. Centro Superior de Estudios sobre el Oriente Próximo y Egipto, Madrid, pp. 521-546.

Webb, S.G., Edwards, P.C., 2002. The Natufian human skeletal remains from Wadi Hammeh 27 (Jordan). Paléorient 28 (1), 103-124.

Webb, S.G., Edwards, P.C., 2013. The Human Skeletal Remains and their Context. In: Edwards, P.C. (Ed.), Wadi Hammeh 27, an Early Natufian Settlement at Pella in Jordan. Brill, Leiden, pp. 367-382.

Weintsein-Evron, M., 2009. Archaeology in the Archives. Unveiling the Natufian Culture of Mount Carmel. Brill, Boston, Leiden.

Wright, K.I., 1994. Ground stone tools and hunter-gatherer subsistence in Southwest Asia: implications for the transition to farming. Am. Antiq. 59, 238-263. 